See Article page 724.

\section{Commentary: Just keep spinning}

Demetrios N. Mallios, MD, ${ }^{a}$ and

Michael E. Bowdish, MD, MS ${ }^{\mathrm{a}, \mathrm{b}}$

In October 2018, changes were made to the allocation system used in heart transplantation with the goal of increasing distribution and prioritizing critically ill patients to undergo transplantation sooner. As might be expected, these changes were met with apprehension and questions about whether or not the new system would be successful and what unforeseen consequences might be encountered.

In this issue of the Journal, Ganapathi and colleagues ${ }^{1}$ have provided an elegant, retrospective analysis comparing one-year time intervals immediately before and after the introduction of the new allocation system. Interestingly, the authors note a significant increase in the use of intraaortic balloon pumps and mechanical circulatory support before heart transplantation with the new allocation system. This was accompanied by much shorter waitlist times but increased ischemic times and nearly triple the distance in miles traveled for a given case. Despite the aforementioned changes, there was no significant difference in posttransplantation outcomes up to 1 year from the time of surgery.

Although it would be easy to assume that practice patterns have changed to prioritize earlier use of mechanical circulatory support to take advantage of the new allocation system and get patients to heart transplantation sooner, this has not been proven. Surgeons and clinicians have indeed become more facile in the placement and use of mechanical circulatory support devices with time. Similarly, device quality has improved as well. To better understand what is happening, future studies should focus on stratifying patients based on type of mechanical support before heart transplantation and comparing outcomes through that lens.

\footnotetext{
From the Departments of ${ }^{\text {a }}$ Surgery and ${ }^{b}$ Preventive Medicine, Keck School of Medicine of USC, University of Southern California, Los Angeles, Calif.

Disclosures: The authors reported no conflicts of interest.

The Journal policy requires editors and reviewers to disclose conflicts of interest and to decline handling or reviewing manuscripts for which they may have a conflict of interest. The editors and reviewers of this article have no conflicts of interest.

Received for publication March 16, 2021; revisions received March 16, 2021; accepted for publication March 18, 2021; available ahead of print March 23, 2021.

Address for reprints: Michael E. Bowdish, MD, MS, Keck School of Medicine of USC, University of Southern California, 1520 San Pablo St, HC2 Suite 4300, Los Angeles, CA 90033 (E-mail: Michael.Bowdish@med.usc.edu).

J Thorac Cardiovasc Surg 2023;165:734

$0022-5223 / \$ 36.00$

Copyright (c) 2021 by The American Association for Thoracic Surgery

https://doi.org/10.1016/j.jtcvs.2021.03.063
}

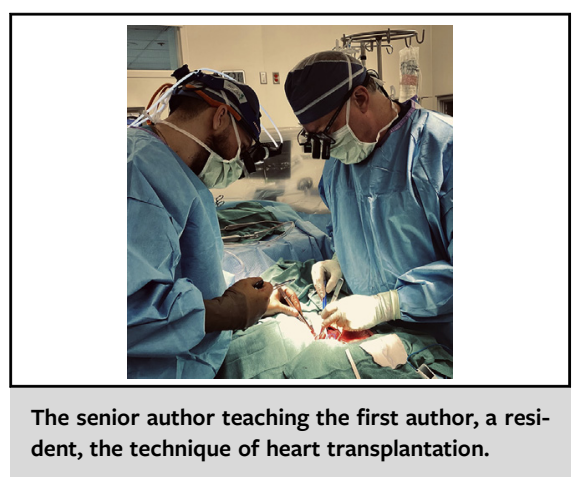

CENTRAL MESSAGE

The ultimate impact of the new

heart allocation system remains

unclear. For now, the pumps will

just keep spinning.

As the authors mention, it is possible that the increasing use of intra-aortic balloon pumps, especially in the axillary position, has allowed for adequate cardiac support with less morbidity and more mobility compared with traditional venoarterial extracorporeal membrane oxygenation. Furthermore, continuing advances in percutaneous pump technology, such as the family of Impella devices (Abiomed, Danvers, Mass), likely will play a growing role in the care of pretransplantation patients. The consequences of these developments and the continued evolution of this complex space are particularly interesting, but rapid changes and variability in practice from center to center make analysis difficult.

In addition, research into the new allocation system's financial consequences would be prudent, particularly given the rising costs in the US healthcare system. Such an investigation would need to consider the cost of hospitalization while on the waitlist and the cost of travel associated with organ procurement and delivery, which can vary geographically. Moreover, mechanical circulatory support has obvious associated costs that may or may not outweigh savings in other realms. Until such questions can be answered, the pumps will just keep spinning.

\section{Reference}

1. Ganapathi AM, Lampert BC, Mokadam NA, Emani S, Hasan AK, Tamer R, et al. Allocation changes in heart transplantation: what has really changed? J Thorac Cardiovasc Surg. 2023;165:724-33.e7. 